\title{
Empirical investigation of two designs of incline solar water desalination system
}

\author{
Phillips O. Agboola*, Fuat Egelioglu \\ Eastern Mediterranean University, Mechanical Engineering Department, Famagusta, via Mersin 10, Turkey \\ * Corresponding author: e-mail: phillips.agboola@cc.emu.edu.tr
}

\begin{abstract}
This paper presents an experimental investigation of two incline solar water desalination (ISWD) systems. One design uses spray jets for spraying water onto the absorber plate, while the other uses a longitudinal slot for getting the inlet water on the absorber plate. The first ever ISWD system constructed and tested by Aybar et al (2005) used the longitudinal slot with a maximum daily production of $2.995 \mathrm{~kg} / \mathrm{m}^{2}$ day. The Aybar et al design produced $3.4 \mathrm{~kg} / \mathrm{m}^{2}$-day while the new design produced $6.41 \mathrm{~kg} / \mathrm{m}^{2}$-day for wick on absorber plate system day during the hottest months in Famagusta (July-August 2010). Also tested was the influence of porous media (wire mesh), wick on the absorber plate. The effect of number of spray jets used in the system on the daily productivity and efficiency of the systems were also investigated.
\end{abstract}

Keywords: Incline solar water desalination system, spray jets, efficiency, potable water, porous media, wick.

\section{INTRODUCTION}

Potable water no longer runs from household taps in Northern Cyprus (N. Cyprus) for two decades now. The municipalities' water, distributed to households, indicate the total dissolved salts (TDS) of around 2000ppm. This water is no good for drinking or cooking. Over the years, the shortage in rainfall in Cyprus and excessive exploration of water in the aquifers has led to seawater intrusion. The seawater intrusions have increased the total dissolved salts in the available aquifers. Each household is expected to provide its potable water. $\mathrm{N}$. Cyprus mainly relies on rain to provide freshwater for various sectors. Increasing fresh water shortage is a serious concern in N. Cyprus, which is,like many other places, suffering from an ongoing shortage of water. Currently at the global level, reverse osmosis (RO) technology is employed to desalinate seawater for the domestic and commercial (mainly hotels) usage. This technology is energy intensive and has adverse effect on the environment. The common RO plants use fossil fuel as the primary energy. N. Cyprus has no oil or gas reserves and is very dependent on imported energy mainly in the form of oil and petroleum products. Also, the high cost of electrical energy (i.e., $0.20 € / \mathrm{kWh}$ ) in $\mathrm{N}$. Cyprus makes RO choice unattractive. Fossil fuels are not a good choice for desalination in N. Cyprus as the fuel prices are almost continuously increasing. High and uncertain increase in fuel costs makes energy intensive desalination techniques unattractive. Moreover, the use of conventional energy sources to drive these technologies has a negative impact on the environment. This is a shortcoming that led to advances in solar desalination innovations. Solar energy is the free, abundant and environmentally friendly energy source. Many authors ${ }^{1-4}$ have attempted a Comprehensive review of desalination and solar desalination. In addition, a number of works ranging from experimental to analytical investigations have been studied on different solar stills with findings available in literature ${ }^{5-12}$. The first Inclined solar water desalination system (ISWD) in N. Cyprus was designed and tested in 2005 by Aybar et al and the findings were recorded ${ }^{13}$. Unlike the solar still system the ISWD feed water runs down on the solar absorber plate and the system produce fresh water and hot water simultaneously. In 2006, Aybar simulated the system using actual deviations of solar intensity and environment temperature during a typical summer day in North Cyprus. According to the simulation, the system can generate 3.5-5.4 $\mathrm{kg}$ (per $\mathrm{m}^{2}$ absorber plate area) distilled water during a day (i.e., 7 am till $7 \mathrm{pm}$ ) with the maximum reached hot water production of $60^{\circ} \mathrm{C}$, and the average water temperature was about $40^{\circ} \mathrm{C}^{14}$.

N. Cyprus, an Eastern Mediterranean island, has relatively high rates of solar insolation throughout a year. Summer days are rather warm and prolonged and the winter is mild; the daily average sunny periods range from 5.5 to $12.5 \mathrm{hrs}$ through the seasons ${ }^{13}$. The daily average global radiation, drops to its minimum, 2.3 $\mathrm{kWh} / \mathrm{m}^{2}$, in December and January. The maximum daily average global radiation is around $8.1 \mathrm{kWh} / \mathrm{m}^{2}$ in July and August. The annual average of daily sunny periods and daily global radiation is about $9 \mathrm{hrs}$ and $5 \mathrm{kWh} / \mathrm{m}^{2}$, respectively ${ }^{15}$. Therefore, solar or solar assisted desalination will be a good choice for N. Cyprus.

In this research work to improve the efficiency/daily productivity of the solar desalination systems, this work intends to present the findings of two ISWDs systems. One of the systems is the ISWD tested by Aybar at al. (2005), which is set as the control system, while the other system includes spray jets and thicker absorber plate to improve the efficiency and daily production. The two systems performances were analyzed performing the experiments under the same weather condition. Effects of wick (natural cotton) on absorber plate and porous media on absorber plate on the performance of the ISWD were also carried out. Also, the work studied the effects of variation in the jets number.

\section{EXPERIMENTAL SET UP AND INSTRUMENTATION}

In order to measure the effects of the spray jet on the incline solar water desalination system effectively, two ISWD systems were constructed. The two systems concurrently investigated under the same climatic condition of Famagusta for daily performance and productivity. 


\section{ISWD System "A"- Control System}

The system tagged system "A" was the first ever ISWD system as designed and constructed by Aybar et al $(2005)^{13}$. This system is set as the control system to measure and analyze the effects of various inclusions in the new design. The schematic diagrams of the system " $A$ " is as shown in Figure 1. The system has an inclined absorber plate (transmissivity of about 0.88 ) of $0.2 \mathrm{~mm}$ thickness and a $3 \mathrm{~mm}$ top glass glazing cover. Glass glazing, which also acts as the condenser, is parallel to the absorber plate. The overall size of the system is $1 \mathrm{~m}$ $\mathrm{x} 1 \mathrm{~m} \times 0.2 \mathrm{~m}$. The surface area of the absorber plate is $1 \mathrm{~m} \times 1 \mathrm{~m}$ and the distance between the absorber plate and the glazing is $0.2 \mathrm{~m}$. The absorber plate was painted with matt black to increase the surface absorptivity (absorptivity of 0.96 and emissivity of 0.08 ). The sides and the bottoms of the system were constructed from stainless sheet metal for better resistance to corrosion. The system bottom and the sides were insulated by the $2 \mathrm{~cm}$ thick Styrofoam. The system was inclined to an angle of $30^{\circ}$ for optimal utility of the $1 \mathrm{~m}^{2}$ surfaces (solar radiation incidence) of the plates ${ }^{\mathbf{1 3}}$. The incline angles also allow water flow through the whole length and width of each surface. For the inlet water, the system uses a longitudinal pipe of $0.8 \mathrm{~m}$ with 8 slots of $2 \mathrm{~mm}$ diameter holes at $0.1 \mathrm{~m}$ apart from each on the longitudinal pipe. As shown below, the water spread was not uniform in this system. The distribution of the inlet water from the longitudinal slots onto the metal absorber plate was not even over the width but flow in a stream wise. Aybar et al (2005) also recorded this shortcoming. K-type thermocouples were attached to various points on the system to measure the system inlet water temperature, system exit water temperature, the absorber plate temperature, cover glass surface temperature, air temperature within the system (cavity air temperature), and the ambient air temperature. The temperature readings were recorded by the ten-channel Digital thermometer (MDSSi8 Series digital, Omega) $\pm 0.5^{\circ} \mathrm{C}$ accuracy. A calibration test on the thermocouple shows accuracy reading of $\pm 0.15^{\circ} \mathrm{C}$. The solar radiation was measured using the Eppley Radiometer Pyranometer (PSP) coupled to a solar radiation meter model HHMiA digital, Omega $0.25 \%$ basic dc accuracy and a resolution of \pm 0.5 ranging from a value of $0-2800 \mathrm{Wm}^{-2}$. The experiment was performed between July and August 2010 under the climatic condition of Famagusta, Northern Cyprus $\left(35^{\circ} 11^{\prime} \mathrm{N} 33^{\circ} 22^{\prime} \mathrm{E}\right)$. Based on the previous study by Hikmet et $\mathrm{al}^{13,14}$, the inlet

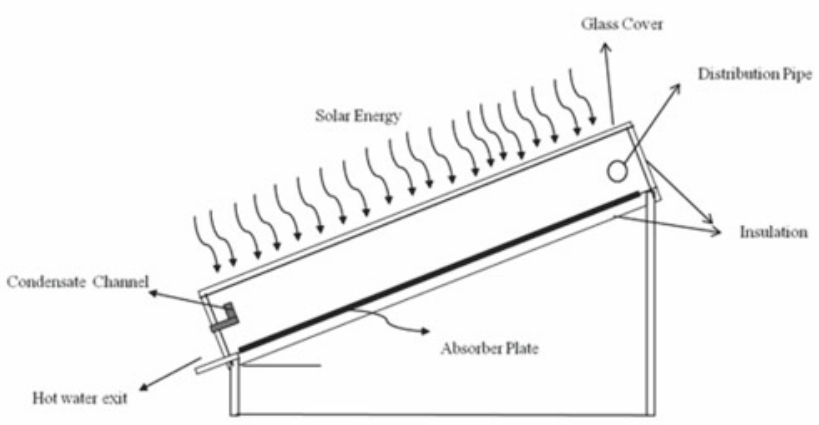

Figure 1. Schematic diagram of the inclined solar water distillation; System A water mass flow rate of about $120 \mathrm{ml} / \mathrm{min}$ was reported as optimum for the system. The water inlet flow rate of about $120 \mathrm{ml} / \mathrm{min}$ was used in this study ${ }^{\mathbf{1 3}}$. The experiment duration was between 8:00 am to 5:00 pm.

\section{ISWD System "B"}

The ISWD system "B" is the new design with spray jets instead of the use of $0.8 \mathrm{~m}$ longitudinal pipe for the inlet water. The system is of $1 \mathrm{~m} \mathrm{x} 1 \mathrm{~m} \mathrm{x} 0.4 \mathrm{~m}$. The schematic diagram of the system " $\mathrm{B}$ " is shown in Figure 2. Like the system "A" it consists of an inclined absorber plate, a cover glass glazing and a cavity, well insulated from the bottom and sides. The absorber plate thickness is $0.4 \mathrm{~mm}$ (for high storage). Glass glazing of $3 \mathrm{~mm}$ was also used in system "B". The cover glass (transmissivity of about 0.88 ) is parallel to the absorber plate. The system absorber plate is a galvanized steel of $0.4 \mathrm{~cm}$ thick with $1 \mathrm{~m}^{2}$ surface area. The absorber plate was matt black painted to enhance the surface absorptivity (absorptivity of 0.96 and emissivity of 0.08 ). The sides and the bottom of the system were constructed from stainless sheet metal for better resistance to corrosion (same goes for system "A"). The bottoms and the sides were insulated by the $2.5 \mathrm{~cm}$ thick Styrofoam. The angle of inclination was also $30^{\circ}$ for optimal utility of the $1 \mathrm{~m}^{2}$ surfaces (solar radiation incidence) of the plates according to Aybar et $\mathbf{a l}^{\mathbf{1 3}}$. The inlet water was sprayed for 60 seconds at 15 minutes intervals onto the absorber plate (i.e 4 minutes of spray in one hour). The diaphragm pump used for the system consumed about $0.1 \mathrm{~kW} / \mathrm{h}$ of electricity and produce $0.7 \mathrm{MPa}$ pressure. The use of the diaphragm pump for 4 minutes in an hour means the system energy consumption is very small. The water falling onto the metal absorber plate through the pressurized jets was evenly distributed over the width and length of the absorber plate. To optimize the heat from the absorber plate a test with wick on the absorber plate and wire mesh on absorber plate were investigated. The introduction of the spray jets was to overcome the unevenly distribution of the inlet water on the absorber plate. A drawback was reported in the work of Aybar et al (2005). Some of the water sprayed on the absorber plate evaporated (after gaining heat energy) and condensed under the glass. The condensate flowing into a condensate channel was extracted from the cavity by a small pipe that extrude from the condensate channel to a plastic water collector outside the systems. The remaining water (hot) was collected through an exit and re-fed to the feed water tank placed near the ISDWs.

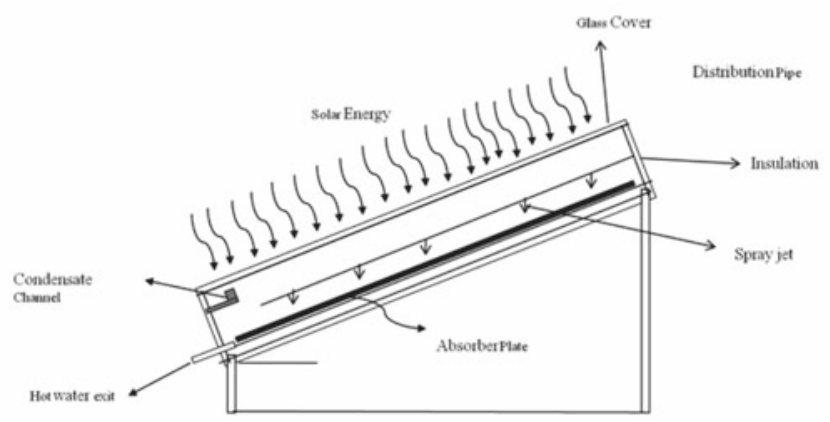

Figure 2. Schematic diagram of the inclined solar water distillation; System B 
The increase in the feed water temperature increases the efficiency of the system. The thermocouples were fixed both at the inner and outer parts of the systems to read various temperatures such as the absorber plate temperature, the ambient air temperature, the inner glass surface temperature, air temperature within the system, feed water inlet and outlet temperatures, cavity air temperature. The duration of the experiments was same as that of system " $A$ ". In addition, the inlet water mass flow rate of $120 \mathrm{ml} / \mathrm{min}$ was used as reported as the optimum for the system by Aybar et al.

\section{INCLINED SOLAR WATER DESALINATION EFFI- CIENCY}

An instantaneous efficiency ( $\eta$ i) of inclined solar water desalination is defined as the ratio of the energy used for water production to the total solar radiation rate given by:

$\eta_{\mathrm{i}}=\frac{Q_{e v}}{H A_{b}}$

$Q_{e v}=m_{e v} L$

Where $Q_{e v}$ is the evaporative heat transfer $(\mathrm{W}), \mathrm{m}_{\mathrm{ev}}$ is the distilled water production rate $\left(\mathrm{kg} / \mathrm{m}^{2} \mathrm{~h}\right), A_{b}$ is the absorber plate area $\left(\mathrm{m}^{2}\right), \mathrm{H}$ is the total solar radiation on the ISWD surface $\left(\mathrm{W} / \mathrm{m}^{2}\right)$.

ISWD daily efficiency, $\eta_{d}$, is obtained by summing up the hourly condensate production multiplied by the latent heat of vaporization (L), and divided by the daily average solar radiation over the solar still area and calculated from the following equation:

$\eta_{d}=\frac{\int_{0}^{t} m_{e v} L d t}{3600 \mathrm{~A} \int_{0}^{t} H d t}$

Where $\mathrm{t}$ is the time $(\mathrm{h}), \mathrm{L}$ is the latent heat of vaporization $(\mathrm{kJ} / \mathrm{kg}), \mathrm{m}_{\mathrm{ev}}$ is the mass of distillate per hour $(\mathrm{kg} /$ $\mathrm{Sec})$. The daily efficiency of the ISWDs is presented in the following section.

\section{EXPERIMENTAL RESULTS AND DISCUSSION}

\section{System "A" vs. System "B"}

The experimental work was performed between the month of July and August 2010 on different clear days under the climatic condition of North Cyprus. The experimental data presented in the following analysis are chosen from some clear sky days. Figure 3 show the hourly variation of the measured solar intensity I for system "A" and system "B", respectively. Figures $3 \mathrm{a}$ and $3 \mathrm{~b}$ show close weather conditions for the days selected. Solar radiation reached the maximum value of $986 \mathrm{~W} / \mathrm{m}^{2}$ (at 1:00PM). High solar radiation as seen in Figure 3 explained the high temperature distribution in the system " $\mathrm{A}$ " and " $\mathrm{B}$ ", there is a direct correlation between high solar radiation and ambient temperature. For comparison, the temperature profiles as depicted in Figures $4 \mathrm{a}$ and $3 \mathrm{~b}$ follow the solar radiation curves as can be seen in Figures $3 a$ and $3 b$. Figure 4 show the temperature distribution (glass temperature, cavity air temperature, absorber plate temperature and the ambient temperature) of the two systems. Fig. 4 a shows that a)

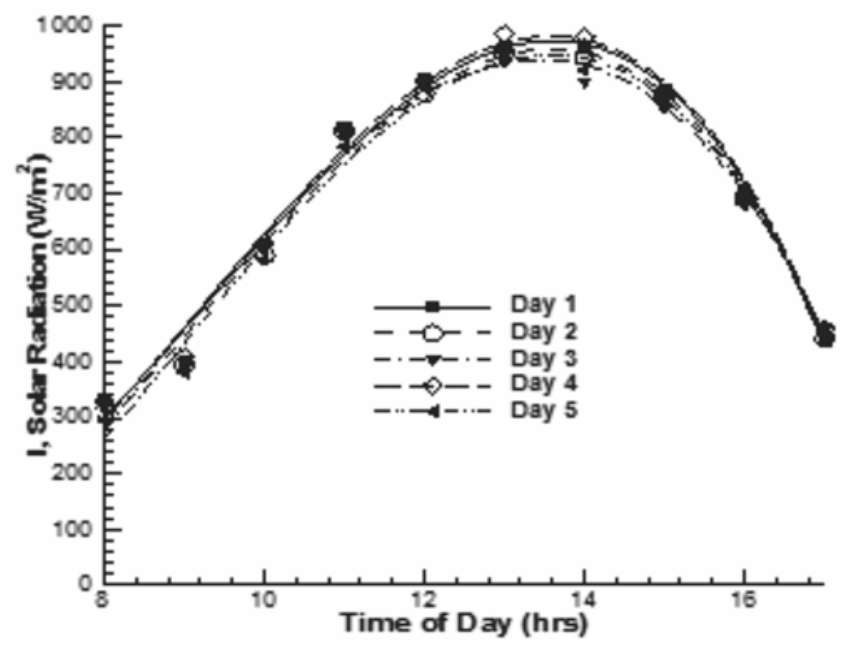

b)

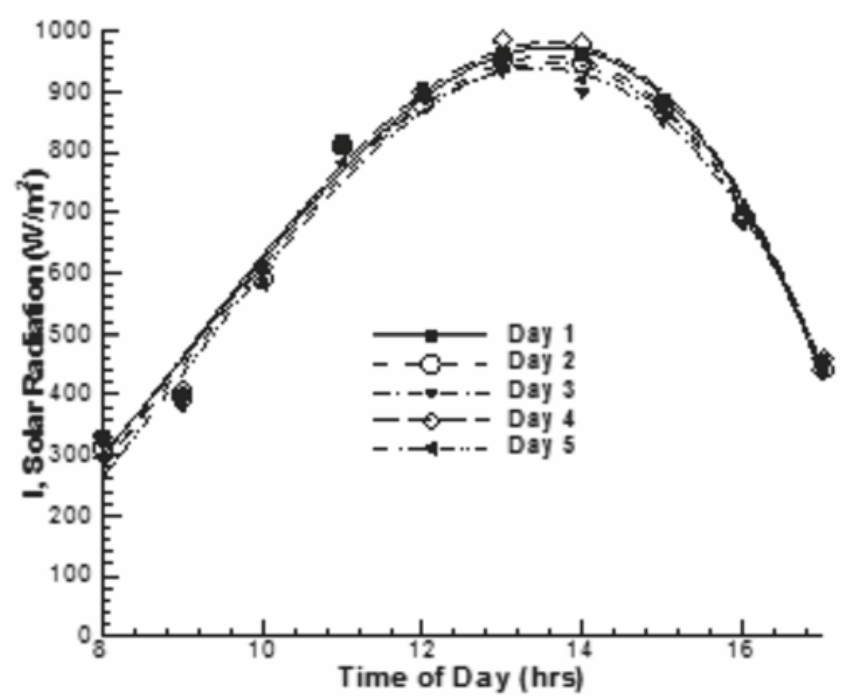

Figure 3. Hourly variation of solar intensity versus local time in (a) System "A" (b) System "B"

the temperature difference between the absorber plate and the cavity air within the early hour of the day were close compared with the wide temperature difference during the afternoon hours of the day. This was due to the thickness of the absorber plate in system "A". It will be seen from Figure $4 \mathrm{~b}$ that there is consistency in the temperature difference of the absorber plate and the cavity air temperature. The temperature difference between the cavity air and the cover glass (in this case the condenser) is a major factor for the production rate. This temperature differences as seen in Figure 4 shows that the system " $B$ " has a wider temperature difference than system "A". The effect of thickness of the absorber plate in system " $\mathrm{B}$ " is seen as the reason for the high temperature profile in the system distribution as compared to the temperature distribution in system "A". A higher temperature difference encourages more convection, which explains the huge difference in the daily production of the two systems. The maximum ambient temperature recorded was $36^{\circ} \mathrm{C}$ (at 1:00PM) for both systems. The temperature distribution of the systems increases with the time of the day, solar radiation and ambient temperature until around 1:00PM, afterwards, all the temperature decrease with the decrease in solar radiation and ambient temperature. Increase in the sys- 
a)

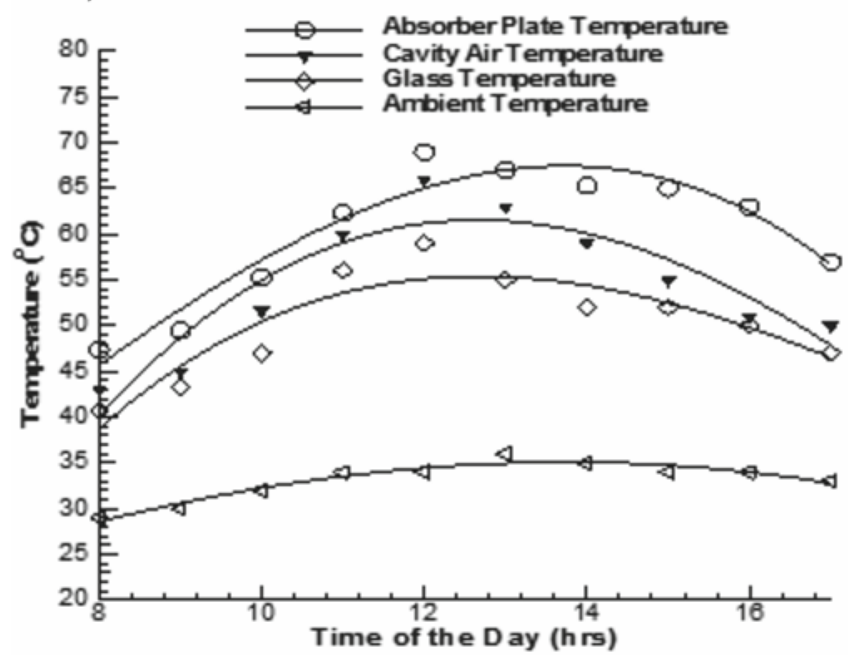

Figure 4. A typical temperature distribution; (a) System "A"

tems temperatures with the increase in solar radiation and/or ambient temperature is as expected and agrees with the findings of Aybar et al (2005). A high solar radiation and /or ambient temperature will improve the daily production of the system. System "A" was exposed to the same weather conditions as system "B" but yielded a low daily production $\left(3.25 \mathrm{~kg} / \mathrm{m}^{2}\right.$ day $)$ when compared to system "B" $\left(5.46 \mathrm{~kg} / \mathrm{m}^{2}\right.$ day). The huge variation in the daily production of system "A" and system "B" can only

a)

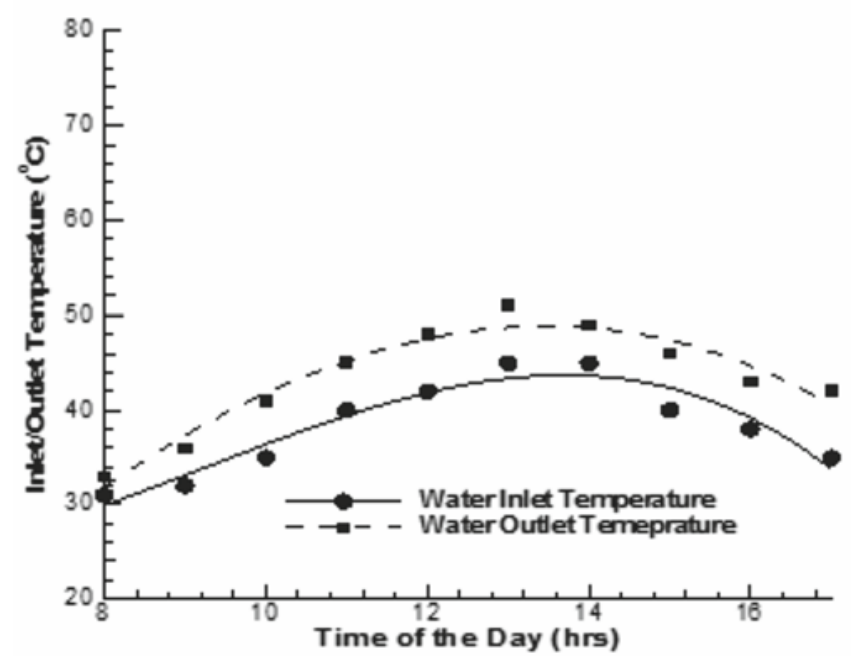

b)

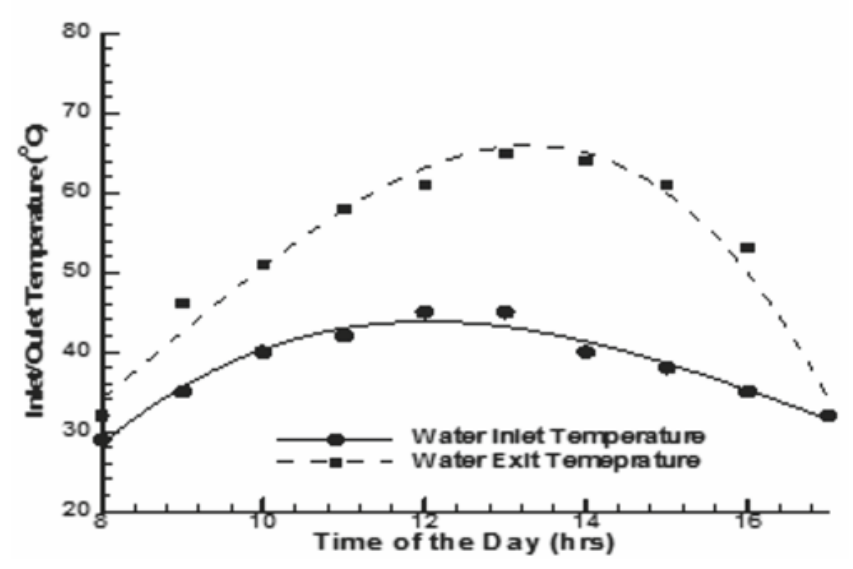

Figure 5. Water inlet temperature and water exit temperature ;(a) System "A" (b) System "B" b)

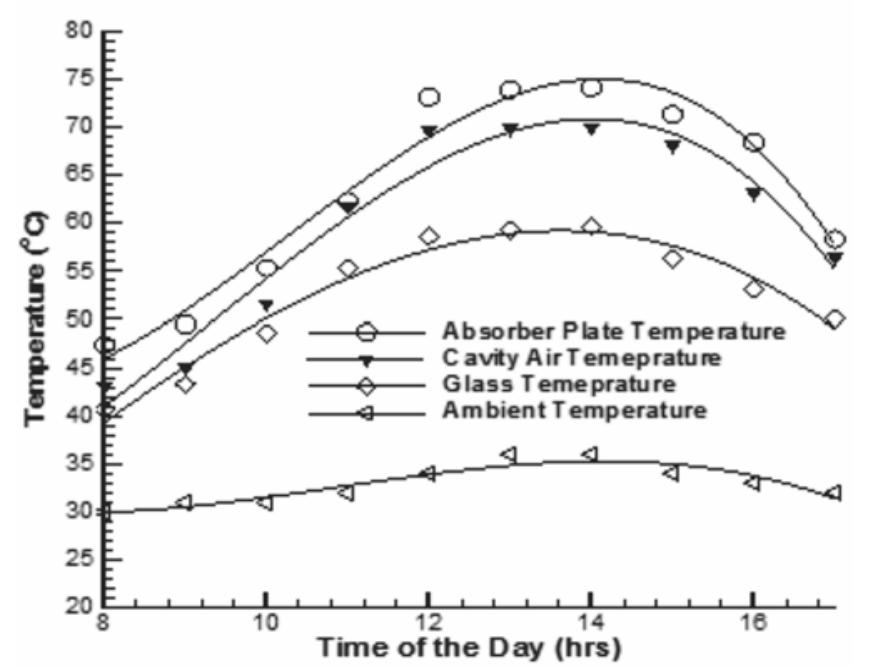

(b) System "B"

be explained due to the differences in the design. The inclusion of jets nozzle for spraying the inlet water and the thickness of the absorber plate plays a major role in the high productivity of system "B". Figure 5 presented the variation in the hourly inlet and the exit temperature of the systems. The inlet water absorbs energy when it runs on the absorber plate. The energy that the water absorbed resulted into evaporation while the rest of the water runs out to the exit as hot water. The use of this hot water as part of the feed water improves the efficiency and production. In Figure 5a, the exit water was not re-injected into the feed. The effect of re-injecting the exit water (hot water) into the feed water raises the temperature of the feed water significantly as seen in Figure $5 \mathrm{~b}$. The high temperature feed water in system "B" influences the convective heat transfer coefficient that translated into high condensation in the system. Figure 6 shows the variation of water production rate for the systems. The production rate is higher for System "B" than for System "A". In system "A" the maximum production rate reaches $0.67 \mathrm{~kg} / \mathrm{h}$ around $1: 00 \mathrm{pm}$ while the maximum production rate for System "B" reaches $0.85 \mathrm{~kg} / \mathrm{h}$ around the same time. System "B" has accumulated water production of $5.46 \mathrm{~kg} / \mathrm{m}^{2}$ day while system "A" has accumulated water production of $3.25 \mathrm{~kg} / \mathrm{m}^{2}$ day under the same climatic conditions. The increase in the daily production of system " $\mathrm{B}$ " is attributed to the efficient spread of the inlet water on the absorber plate surface. System "B" optimizes the heat energy on the

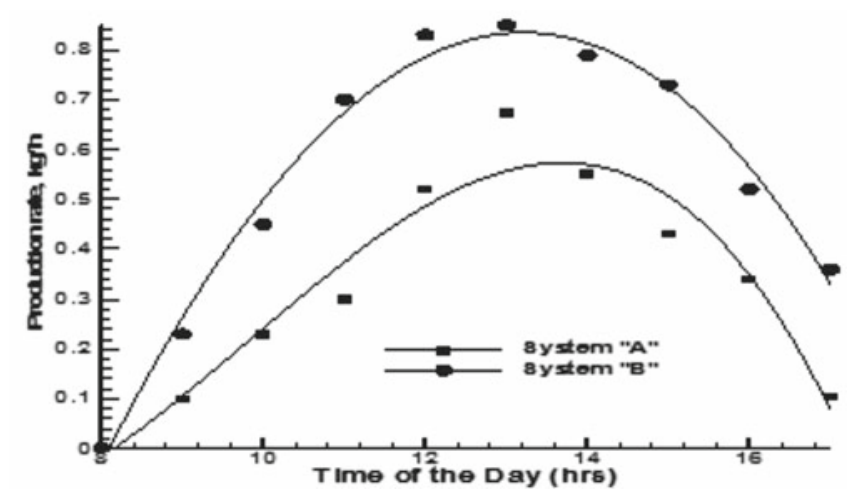

Figure 6. Variation of production rate of the systems 
absorber plate surface due to the even distribution of the inlet water unlike system "A", where the inlet water forms a stream pattern on the absorber plate and uses some of the heat energy. The daily efficiency of the systems is 40.1 and 48.3 , respectively.

\section{System "B" with wick and wire mesh}

The inclusion of the wick shows better performance than using the bare absorber plate ${ }^{15-16}$; the only explanation for this is that water easily runs through the absorber plate without the galvanized material holding the water, unlike the wick with the ability of soaking itself with the water. From Figure 7, the daily production of system "B", system "B" with wick and system "B" with wire mesh(as the porous media) is given as 5.46, 6.41 and $3.03\left(\mathrm{~kg} / \mathrm{m}^{2}\right)$ and with the daily efficiency of $48.3 \%, 50.3 \%$ and $32.6 \%$, respectively. The wick material, natural cotton in this case, aid evenly the distribution of feed water for efficient use of the absorb heat by the absorber plate. The combine effect of the wick and jets spray in system "B" effectively eliminates the problem of the unevenly feed water distribution as motioned by Aybar et al (2005) as one reason for low daily production. The use of porous media in System "B" did not work as expected; the wire mesh application is limited to the solar air heater. In order to optimize the spray jets position for best results, six spray jets were fixed as shown in Figure 8. The area of the absorber plate was divided into 8 parts $(0.25 \mathrm{~m} \mathrm{x} 0.25 \mathrm{~m}$ each $)$. Figure 9 shows the variation of hourly production of system "B" different numbers of spray jets. The sequence of the number of jets tested on the system was 2, 4 and 6 for optimum performance. This study is the first to test the effect of spray jet on the solar desalination system. From Figure 9 it was discovered that two spray jets arranged at P1 and P11 performed best. When 4 and 6 arrangements of spray jets were used the system produced more hot water than fresh water but with two

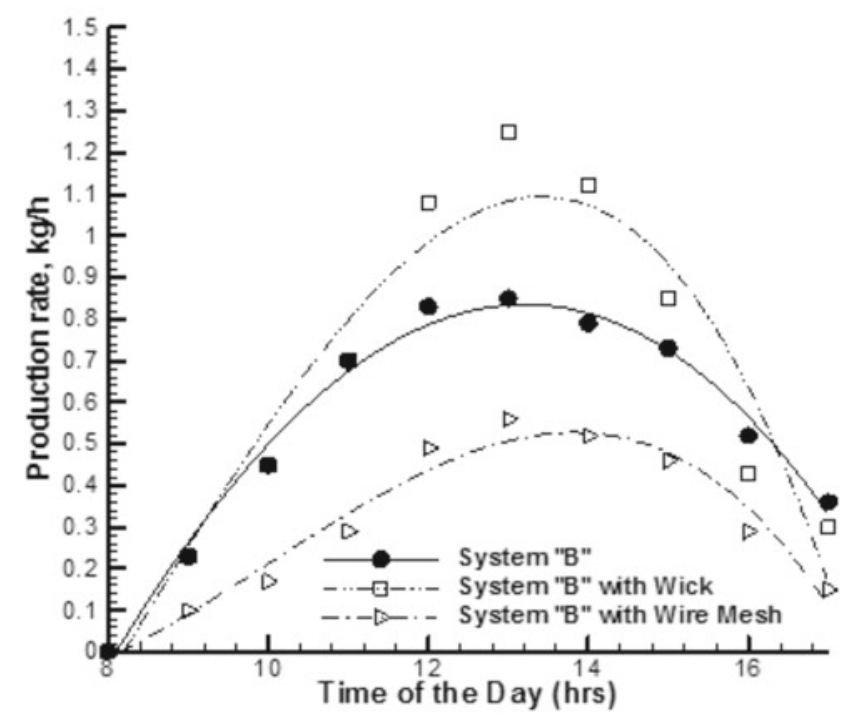

Figure 7. Hourly production rate for System "B", System "B" with Wick and System "B" with wire mesh

\begin{tabular}{|c|c|}
\hline P1 & P11 \\
\hline P2 & P22 \\
\hline P3 & P33 \\
\hline
\end{tabular}

Figure 8. Spray jets positions on the absorber plate

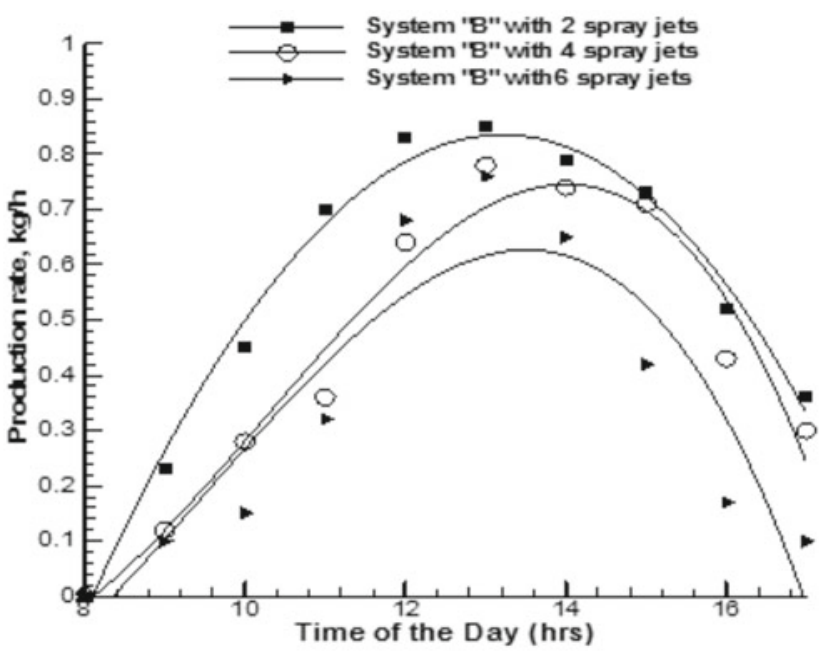

Figure 9. Effects of spray jets number on daily production; System "B"

spray jets the system produced more fresh water than hot water. Another thing noted was that the hot water produced by using two spay jets is hotter than that of four spray jets and that of four spray jet is hotter than that of six spray jets.

One major difficulty encountered in this experiment is the loss of heat energy through the top glass; seasonal wiping of the glass surface with water minimized this problem. The replacement of the longitudinal tube used in system "A" with spray jets in System "B" improves the ISWD system by about $49.9 \%$, the cost of using the spray jets (pump used) is about $0.2 \$ /$ day, which is very small compared with the improvement on the system.

\section{CONCLUSIONS}

In this paper, experimental investigations of the performance of two ISWD systems were presented. The two systems were tested concurrently under the climatic condition of Famagusta, Northern Cyrus. The two systems were analyzed and compared in terms of performance, daily production and efficiency. The variation of the production rate, cumulative production, glass temperature, absorber temperature and cavity air temperature are analyzed for system "A" and system "B". The experimental results show that daily production increases with solar radiation and ambient temperature. System "B" with wick showed a better result than system "B". System "B" with wire mesh shows poor performance when compared with system "B". The effect of spray jets is very significant on the daily performance of system B improving the system performance in terms of daily production by $40.5 \%$. The effect of the number of spray jets on the daily performance of system B with wick was also significant to the daily fresh water production. The cost of operating the spray jets is insignificant compared to the effect it has on the system. The daily production of system A is given as $3.25 \mathrm{~kg} / \mathrm{m}^{2}$ and with the daily efficiency of $40.1 \%$ while the daily production of System " $\mathrm{B}$ " is given as 5.46 , with daily efficiency of $48.3 \%$. The daily production of system "B", system "B" with wick and system " $\mathrm{B}$ " with wire mesh(as porous media) is given as $5.46,6.41$ and $3.03\left(\mathrm{~kg} / \mathrm{m}^{2}\right)$ and with the daily efficiency of $48.3 \%, 50.3 \%$ and $32.6 \%$, respectively. The use of porous media in System "B" did not work 
as expected; the wire mesh application is limited to the solar air heater.

\section{LITERATURE CITED}

1. Delyannis, E. (2003). Historic background of desalination and renewable energies. Solar Energy. 75, 357-366. DOI: 10.1016/j.solener.2003.08.002.

2. Tiwari, G.N., Singh, H.N. \& Tripathi, R. (2003). Present status of solar distillation. Solar Energy. 75, 367-373. DOI: 10.1016/j.solener.2003.07.005.

3. Murugavel, K.K., Chockalingam Kn, K.S.K. \& Srithar, K. (2008). An experimental study on single basin double slope simulation solar still with thin layer of water in the basin. Desalination. 220, 687-693. DOI: 10.1016/j.desal.2007.01.063.

4. Badran, O.O. (2007). Experimental study of the enhancement parameters on a single slope solar still productivity. Desalination. 209, 136-143. DOI: 10.1016/j.desal.2007.04.022.

5. Al-Hinai, H., Al-Nassri, M.S. \& Jubran B.A. (2002). Parametric investigation of a double-effect solar still in comparison with a single-effect solar still. Desalination. 150, 75-83. DOI: 10.1016/S0011-9164(02)00931-1.

6. Al-Karaghouli, A.A. \& Al-Naser, W.E. (2004). Performances of single and double basin solar-stills. Applied Energy. 78, 347-354. DOI: 10.1016/S0306-2619(03)00005-9.

7. Al-Karaghouli, A.A. \& Al-Naser, W.E. (2004). (2004). Experimental comparative study of the performances of single and double basin solar-stills. Applied Energy. 77, 317-325. DOI: 10.1016/S0306-2619(03)00124-7.

8. Agboola, O.P., Atikol, U. \& Assefi, H. (2010). Feasibility of Basin Solar Still in Tehran. Proceeding of $10^{\text {th }}$ International Conference on Clean Energy, 15-17 September 2010. Famagusta, North Cyprus.

9. Ismail, B.I. (2009). Design and performance of a transportable hemispherical solar still. Renewable Energy. 34, 145-150. DOI: 10.1016/j.renene.2008.03.013.

10 Arjunan, T.V., Aybar, H.S. \& Nedunchezhian, N. (2009). Status of Solar desalination in India. Renewable and Sustainable Energy Reviews. 13, 2408-2418. DOI: 10.1016/j.rser.2009.03.006.

11. Samee, M.A., Mirza, U.K., Majeed, T. \& Ahmad, N.(2007). Design and performance of a simple single basin solar still. Renewable and Sustainable Reviews. 11, 543-549. DOI: 10.1016/j.rser.2005.03.003.

12. Abu-Hijleh, B.A.K. \& Rababa'h, H.M. (2003). Experimental study of a solar still with sponge cubes in basin. Energ. Convers. Manag. 44(9), 1411-1418. DOI: 10.1016/ S0196-8904(02)00162-0.

13. Aybar, H.S., Egelioglu F. \& Atikol U. (2005). An experimental study on an inclined solar Distillation System. Desalination. 180, 285-289. DOI: 10.1016/j.desal.2005.01.009.

14. Aybar, H.S. (2006). Mathematical modeling of an inclined solar water distillation system. Desalination. 190, 63-70. DOI: 10.1016/j.desal.2005.07.015.

15. Abdel-Rehim, Z.S. \& Lasheen, A. (2005). Improving the performance of solar desalination systems. Renew. Ener. 30, 1955-1971. DOI: 10.1016/j.renene.2005.01.008.

16. Al-karaghouli, A.A. \& Minasian, A.N. (1995). A floating-wick type solar still. Renew. Energ. 6, 77-79. DOI: 10.1016/09601481(94)00047-A. 